\title{
Compressive Behavior of Concrete with Vitrified Soil Aggregate
}

\author{
By Shane M. Palmquist, ${ }^{1}$ Student Member, ASCE, Daniel C. Jansen, ${ }^{2}$ and \\ Christopher W. Swan, ${ }^{3}$ Associate Members, ASCE
}

\begin{abstract}
The compressive behavior of portland cement concrete with vitrified soil coarse aggregate is the focus of this paper. A total of 10 batches of concrete were examined at four different coarse aggregate volume fractions with three different combinations of vitrified and natural coarse aggregates. For comparison purposes, the ratios of cement, water, and fine aggregates were held constant. The stress-strain curves, modulus of elasticity, compressive strength, and Poisson's ratio are examined as a function of coarse aggregate content. Results show a decrease in compressive strength as the volume fraction of vitrified soil aggregate increased. Moduli of elasticity for concrete with vitrified soil aggregate are considerably higher than concrete with natural aggregate. The Hirsch-Dougill model is extended and applied to a three-phase material to predict the modulus of elasticity of concrete with natural and vitrified soil aggregates.
\end{abstract}

\section{INTRODUCTION}

Vitrified soils are solid glasslike material resembling volcanic obsidian. They are the products of contaminated soils treated by high-temperature thermal remediation called vitrification, a technique that heats soils contaminated with organic compounds or inorganic compounds (heavy metals) to temperatures of $1,600^{\circ}$ to $2,000^{\circ} \mathrm{C}$. While organics are destroyed, remaining contaminants are immobilized within the solidified product (Hansen and Fitzpatrick 1991; USDoD 1994). The process can be done either in situ or ex situ, making it ideal for large masses of contaminated soils. The resulting product, vitrified soils, is no longer federally classified as a hazardous material and may be suitable as an aggregate in concrete.

The need to develop concrete with nontraditional aggregates has risen due to environmental trends as well as economic reasons (Brown 1998; Shelburne and Degroot 1998). Demand has increased so that such materials as newspapers, carpet fibers, chicken feathers, and soda containers that are typically deposited in landfills may be used in concrete (Ali and Greenwell 1998). Materials that have been studied in concrete include reclaimed concrete, reclaimed asphalt, industrial byproducts, rubber, plastics, and glass.

Reclaimed concrete from demolished structures can be crushed into aggregate and partially reused (Tavakoli and Soroushian 1996; Ramamurthy and Gumaste 1998). This material has been used as base and subbase materials as well as embankment fill in highway construction (Shelburne and Degroot 1998). Asphalt reclaimed from road surfaces being stripped for repaving has also been used in concrete; portions of this material are suitable for concrete applications including sidewalks, curbs, pipes, and gutters (Delwar et al. 1997).

Industrial by-products represent a large reclaimed group of materials suitable for use in concrete. Some of the predominant by-products are fly ash, silica fume, steel slag, and spent molding sand (Yip and Tay 1990; Navistar 1998). Some industrial

${ }^{1} \mathrm{PhD}$ Candidate, Dept. of Civ. and Envir. Engrg., Tufts Univ., Medford, MA 02155 .

${ }^{2}$ Asst. Prof., Dept. of Civ. and Envir. Engrg., Tufts Univ., Medford, MA 02155.

${ }^{3}$ Assoc. Prof., Dept. of Civ. and Envir. Engrg., Tufts Univ., Medford, MA 02155 . by-products improve certain properties of concrete. For example, fly ash, which is a by-product of burning coal, improves durability, strength, and workability (Ali and Greenwell 1998).

Recycled materials including rubber, plastic, and glass have applications in concrete. Every year in the United States approximately 250 million tires are scrapped. If shredded, the resulting crumb rubber may be used in concrete for infrastructural applications (Eldin and Senouci 1993; Raghavan et al. 1998). Plastics are recycled in large quantities. Shredded plastic from car bumpers has been successfully used in concrete for laboratory experiments (Al-Manaseer and Dalal 1997). It was concluded that the plastic may be suitable as an aggregate in concrete for actual structures. Glass, in crushed or cullet form, is another type of recyclable material that has been used as an aggregate in concrete (Shelburne and Degroot 1998). It has been studied in concrete masonry blocks, and tests on concrete with glass aggregate, including workability, permeability, and shear strength, have been performed to determine the suitability of the material in construction (Shin and Sonntag 1994; Meyer et al. 1996). Smooth, flat surfaces of the crushed material cause the bond between the mortar and glass to be poor (Polley et al. 1998).

Crushed vitrified soils are similar to cullet as they have smooth, flat surfaces and sharp edges. Bond between the mortar and vitrified soil aggregate is expected to be poor, lowering the compressive strength of the concrete. However, the extent of this decrease will depend on the amount of the vitrified aggregate used in the mix. How the amount of crushed vitrified soil aggregate affects the mechanical performance of concrete is investigated herein.

\section{MATERIALS}

\section{Cement}

Type I portland cement meeting the requirements of ASTM C150 was used for all concrete mixes.

\section{Fine Aggregate}

Natural sand with a maximum aggregate size of $4.75 \mathrm{~mm}$ and fineness modulus of 2.79 was used. The sand met the gradation requirements of ASTM C33, and the distribution is shown in Fig. 1. Physical properties including bulk specific gravity, absorption capacity, and effective absorption in accordance with ASTM C127 and C128 were determined and are given in Table 1 (ASTM 1994). 


\section{Coarse Aggregates}

Natural and vitrified coarse aggregates were used. All coarse aggregates met the gradation requirements of ASTM C33 size 8 aggregate, and the distribution is shown in Fig. 1. Physical properties including bulk specific gravity, absorption capacity, effective absorption, and dry rodded unit weight were determined per ASTM C127, C128, and C29 (ASTM 1994). These values are given in Table 1 .

The natural aggregate used, shown in Fig. 2(a), was a subrounded granitic gravel with maximum size of $12.5 \mathrm{~mm}$. This aggregate has surfaces that are rough in texture. Vitrified soils with an original size ranging from 50 to $150 \mathrm{~mm}$ were crushed to a maximum size of $12.5 \mathrm{~mm}$, resulting in vitrified soil aggregates that are highly elongated with sharp edges and smooth surfaces, as shown in Fig. 2(b).

\section{PROPORTIONING, CASTING, AND TESTING}

A total of 10 batches of mortar and concrete were cast and are listed in Table 2. For all batches, the ratio of water:cement: fine aggregate was fixed at 0.57:1:1.96 by weight, and the ratios of coarse aggregate to cement for all batches are given

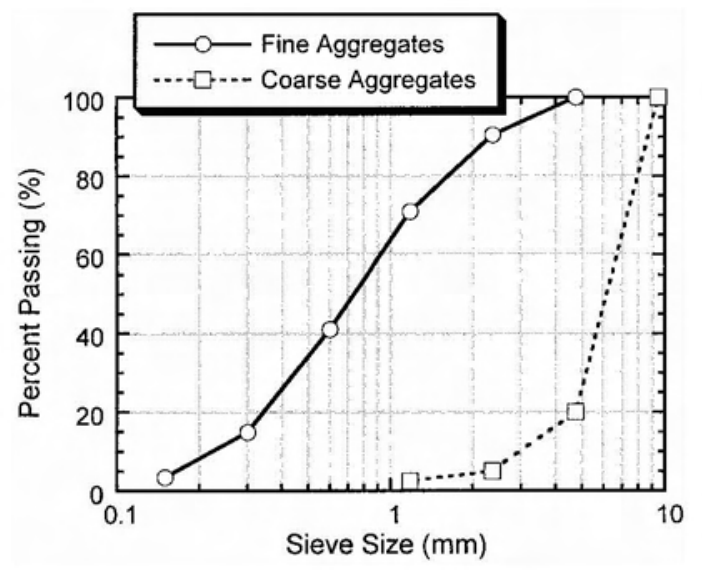

FIG. 1. Gradation of Fine and Coarse Aggregates

TABLE 1. Physical Properties of Aggregates

\begin{tabular}{llcc} 
& \multicolumn{3}{c}{ Aggregate Type } \\
Aggregate property & Fine & $\begin{array}{c}\text { Natural } \\
\text { coarse }\end{array}$ & Vitrified \\
coarse \\
Bulk specific gravity & 2.43 & 2.63 & 2.72 \\
Absorption capacity $(\%)$ & 1.0 & 1.1 & 0.2 \\
Effective absorption $(\%)$ & 0.5 & 0.9 & 0.2 \\
Dry rodded unit weight $\left(\mathrm{kg} / \mathrm{m}^{3}\right)$ & - & 1,605 & -
\end{tabular}

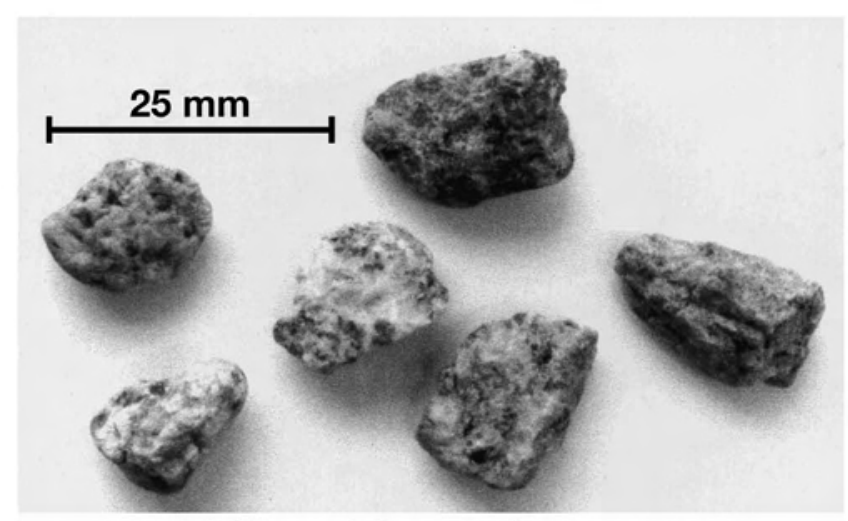

a) Natural Coarse Aggregates

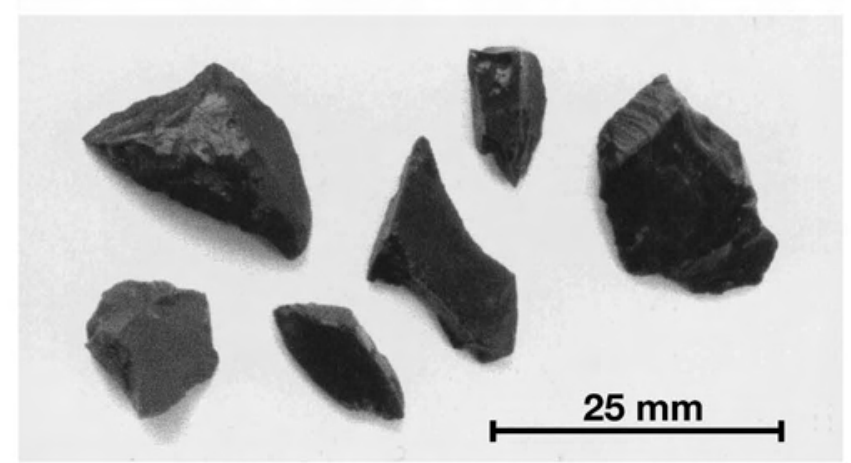

b) Vitrified Coarse Aggregates

FIG. 2. Coarse Aggregates Used in Study

in Table 2. Predicted volume fractions for all the constituents are also given in Table 2. The air content was held at a fixed fraction of $4 \%$ of the total mortar content. Batch $\mathrm{M}$, for mortar, had no coarse aggregates. Concrete batches are designated by the percent of coarse aggregate by volume $(15,33$, or 50$)$ and by the type of coarse aggregate $(N, V$, or $N V)$. Types $N$ or $V$ indicate that only natural or vitrified coarse aggregate is used, respectively, while $N V$ indicates a 50/50 combination of natural and vitrified coarse aggregates.

All concrete was mixed in accordance with ASTM C192 (ASTM 1994). For each batch, three $100 \times 200 \mathrm{~mm}$ cylinders were cast and rodded in three layers and left in the preparation room covered with plastic for approximately $18 \mathrm{~h}$. The cylinders were then demolded and placed in a moist curing room until testing. Prior to testing, the cylinders were capped with a sulfur capping compound per ASTM C617 (ASTM 1994).

All cylinders were tested for compressive strength, modulus of elasticity, and Poisson's ratio per ASTM C469 and C39

TABLE 2. Concrete Constituent Contents

\begin{tabular}{|c|c|c|c|c|c|c|c|c|}
\hline Batch & $\begin{array}{l}\text { Water } \\
(\%)\end{array}$ & $\begin{array}{c}\text { Cement } \\
(\%)\end{array}$ & $\begin{array}{l}\text { Air } \\
(\%)\end{array}$ & $\begin{array}{c}\text { Fine } \\
\text { aggregate } \\
(\%)\end{array}$ & $\begin{array}{c}\text { Natural coarse } \\
\text { aggregate } \\
(\%)\end{array}$ & $\begin{array}{l}\text { Vitrified coarse } \\
\text { aggregate } \\
(\%)\end{array}$ & $\begin{array}{l}\text { Total coarse } \\
\text { aggregate } \\
(\%)\end{array}$ & $\begin{array}{c}\text { Total } \\
\text { CA/cement } \\
\text { by weight }\end{array}$ \\
\hline$M$ & 32 & 18 & 4 & 46 & 0.0 & 0.0 & 0.0 & 0.00 \\
\hline $15 N$ & 28 & 15 & 3 & 39 & 15.0 & 0.0 & 15.0 & 0.80 \\
\hline $15 N V$ & 28 & 15 & 3 & 39 & 7.5 & 7.5 & 15.0 & 0.83 \\
\hline $15 \mathrm{~V}$ & 28 & 15 & 3 & 39 & 0.0 & 15.0 & 15.0 & 0.85 \\
\hline $33 N$ & 22 & 12 & 2 & 31 & 33.0 & 0.0 & 33.0 & 2.28 \\
\hline $33 N V$ & 22 & 12 & 2 & 31 & 16.5 & 16.5 & 33.0 & 2.32 \\
\hline $33 \mathrm{~V}$ & 22 & 12 & 2 & 31 & 0.0 & 33.0 & 33.0 & 2.36 \\
\hline $50 N$ & 16 & 9 & 2 & 23 & 50.0 & 0.0 & 50.0 & 4.63 \\
\hline $50 N V$ & 16 & 9 & 2 & 23 & 25.0 & 25.0 & 50.0 & 4.71 \\
\hline $50 \mathrm{~V}$ & 16 & 9 & 2 & 23 & 0.0 & 50.0 & 50.0 & 4.79 \\
\hline
\end{tabular}




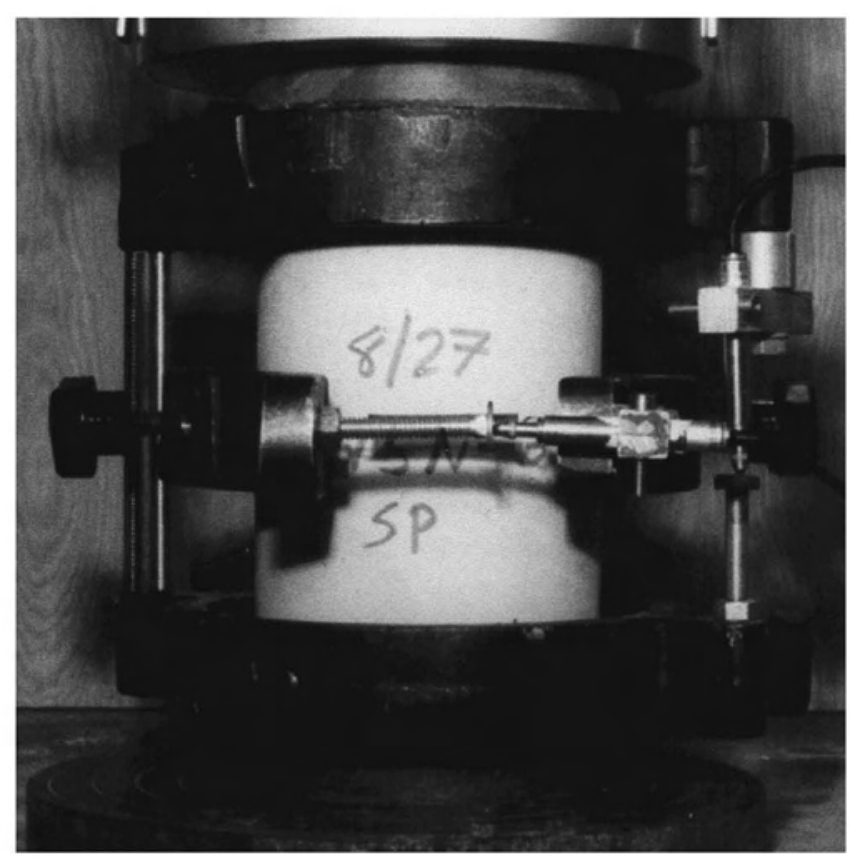

FIG. 3. Compression Test Setup

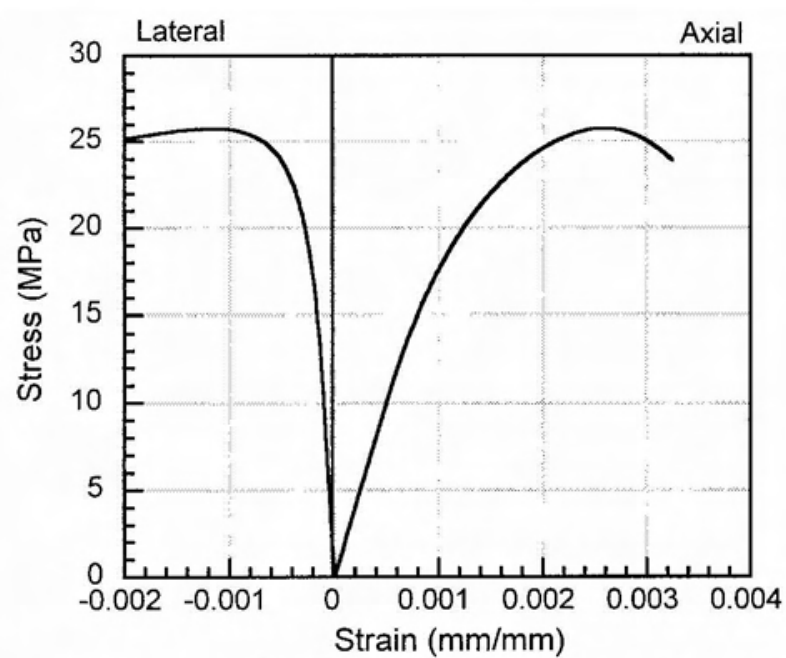

a) Mortar: $0 \%$ Coarse Aggregate by Volume

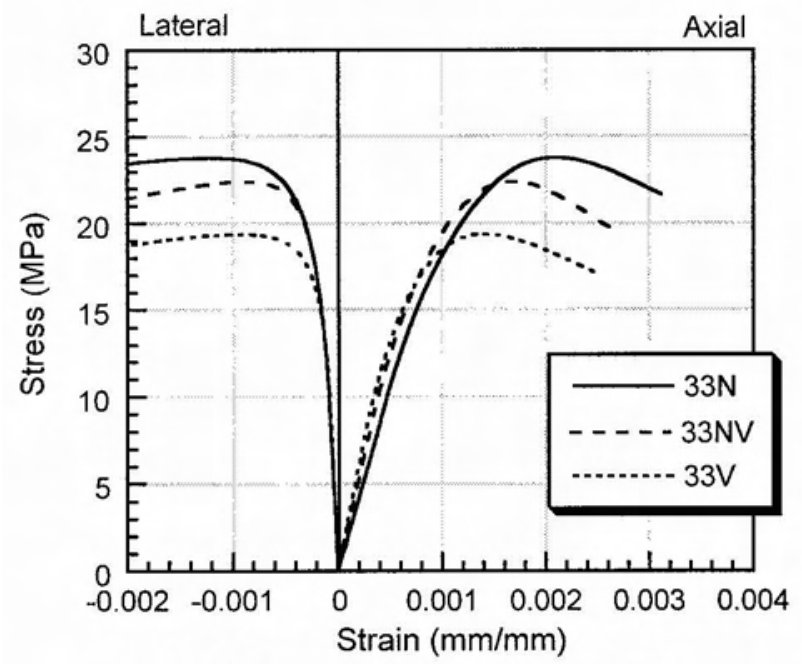

c) $33 \%$ Coarse Aggregate by Volume
(ASTM 1994). The test setup is shown in Fig. 3. In addition, the stress-strain curves for axial and lateral strains up to and beyond the peak stress were measured for each cylinder.

\section{RESULTS}

Representative axial and lateral stress-strain curves for all batches of concrete, including the mortar, are presented in Fig. 4. All curves are continuous and smooth and exhibit pre- and postpeak behavior. Compressive strength, density, modulus of elasticity, and Poisson's ratio are summarized in Table 3.

\section{Compressive Strength}

Fig. 5 shows the compressive strength versus percent coarse aggregate by volume. Increasing the volume fraction of natural coarse aggregate to $15 \%$ (batch $15 \mathrm{~N}$ ), the compressive strength increases by $14.6 \%$. For batches $15 \mathrm{NV}$ and $15 \mathrm{~V}$, there is no apparent increase in compressive strength as compared to the mortar. For all types of coarse aggregate, when the volume fraction increases beyond $15 \%$, there is a steady decline in compressive strength. Also, as the natural coarse aggregate is replaced by vitrified soil, there is a consistent decrease in compressive strength ranging from 15 to $35 \%$, depending on the volume fraction of coarse aggregate and the amount of natural

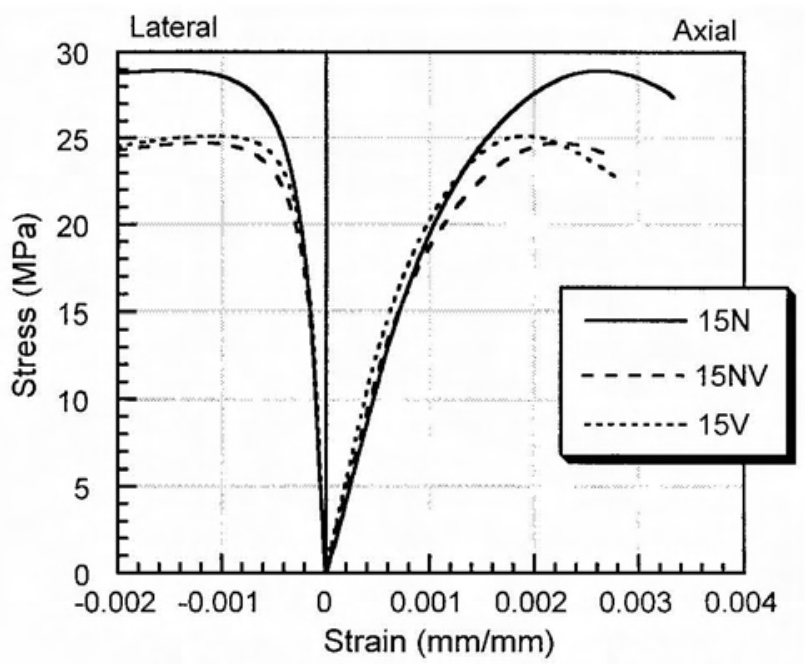

b) $15 \%$ Coarse Aggregate by Volume

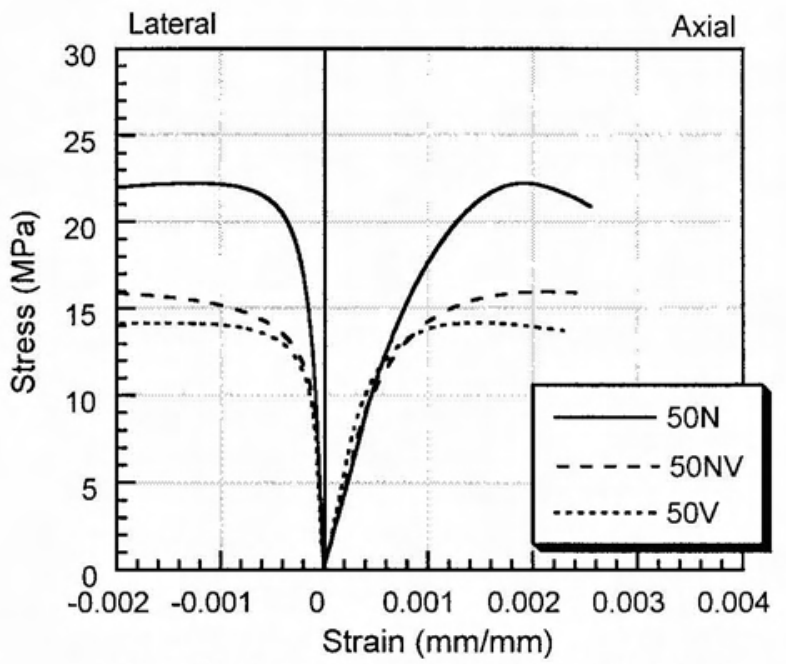

d) $\mathbf{5 0} \%$ Coarse Aggregate by Volume

FIG. 4. Representative Stress-Strain Curves for All Batches 
TABLE 3. Measured Concrete Properties and ACI Modulus of Elasticity Prediction

$\begin{array}{lccc}\text { Batch } & \begin{array}{c}f_{c}^{\prime} \\ (\mathrm{MPa})\end{array} & \begin{array}{c}\rho \\ \left(\mathrm{kg} / \mathrm{m}^{3}\right)\end{array} & \begin{array}{c}E_{c \text {-meas }} \\ (\mathrm{GPa})\end{array} \\ M & 26.0( \pm 0.8) & 2159( \pm 7) & 20.4( \pm 0.3) \\ 15 N & 29.8( \pm 1.2) & 2255( \pm 5) & 23.0( \pm 0.5) \\ 15 N V & 24.8( \pm 0.4) & 2229( \pm 2) & 22.9( \pm 0.1) \\ 15 V & 25.3( \pm 0.5) & 2233( \pm 1) & 26.2( \pm 0.3) \\ 33 N & 24.8( \pm 0.4) & 2310( \pm 1) & 21.4( \pm 0.3) \\ 33 N V & 22.6( \pm 0.2) & 2300( \pm 2) & 25.7( \pm 0.2) \\ 33 V & 19.5( \pm 0.2) & 2297( \pm 1) & 30.3( \pm 0.8) \\ 50 N & 22.3( \pm 0.7) & 2384( \pm 3) & 22.1( \pm 0.5) \\ 50 N V & 16.0( \pm 0.6) & 2356( \pm 9) & 22.6( \pm 1.0) \\ 50 V & 14.4( \pm 0.8) & 2332( \pm 2) & 28.3( \pm 1.1)\end{array}$

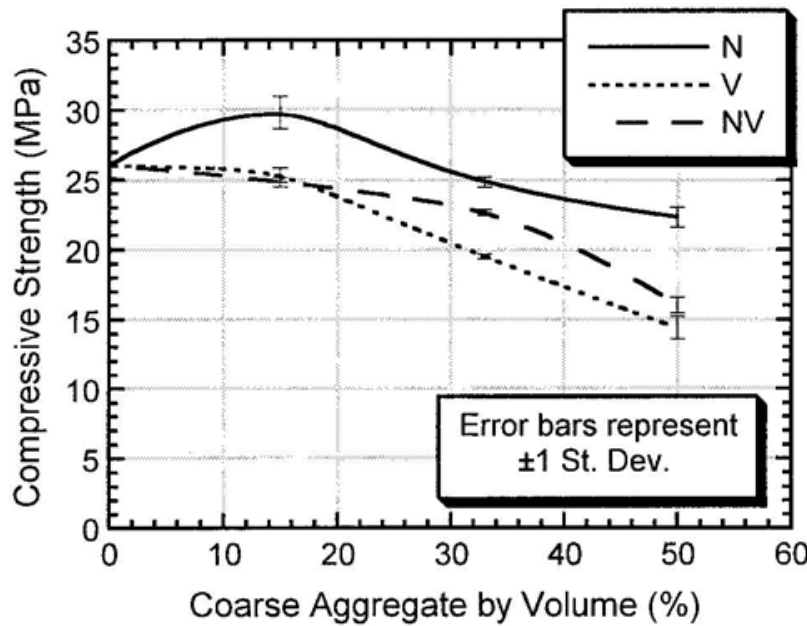

FIG. 5. Compressive Strength versus Coarse Aggregate Content

aggregate replaced by vitrified soil. Similarly, 20 to $30 \%$ decreases in compressive strengths have been reported when approximately one-third of the natural aggregates are substituted with recycled glass by weight (Meyer et al. 1996; Polley et al. 1998).

The decrease in strength can be attributed in two different mechanisms. Poor bond between the mortar and the glasslike surfaces of the vitrified soil is the primary mechanism; the smooth texture of the surface has a significant effect on lowering bond (Giaccio and Zerbino 1986). The secondary mechanism is related to the high angularity of the crushed vitrified soil. As natural coarse aggregate is replaced by equal volumes of vitrified soil, the concrete densities are expected to increase since vitrified soil has a slightly higher specific gravity than the natural coarse aggregate (Table 1); the reverse trend is found, as seen in Table 3 . The decrease in density as vitrified coarse aggregate is used can be attributed to higher air content caused by additional air being entrapped due to the high angularity of the crushed vitrified soil. This finding is contrary to the estimated air contents given in Table 2. The writers also noted that as higher volume fractions of vitrified soil were used, the mixes became increasingly harsh.

\section{Modulus of Elasticity}

Fig. 6 shows the measured modulus of elasticity versus coarse aggregate content for all batches. Concretes with higher moduli of elasticity correspond to those having larger vitrified soil contents; this trend can be directly related to vitrified soil having a high modulus of elasticity (Tuan and Dass 1996). For concretes with all natural coarse aggregates, there is no noticeable change in the modulus of elasticity as the volume fraction increases from 0 to $50 \%$; however, for concretes with vitrified soil aggregates, there is a significant increase in the modulus from 0 to $33 \%$, beyond which the modulus begins to

$\begin{array}{cc}E_{c-\mathrm{ACI}} & \\ (\mathrm{GPa}) & E_{c-\text { meas }} / E_{c-\mathrm{ACI}} \\ 22.0( \pm 0.4) & 0.93 \\ 25.1( \pm 0.5) & 0.92 \\ 22.6( \pm 0.2) & 1.01 \\ 22.8( \pm 0.2) & 1.15 \\ 23.5( \pm 0.2) & 0.91 \\ 22.6( \pm 0.1) & 1.14 \\ 20.9( \pm 0.1) & 1.45 \\ 23.6( \pm 0.4) & 0.94 \\ 19.7( \pm 0.4) & 1.15 \\ 18.4( \pm 0.5) & 1.53\end{array}$

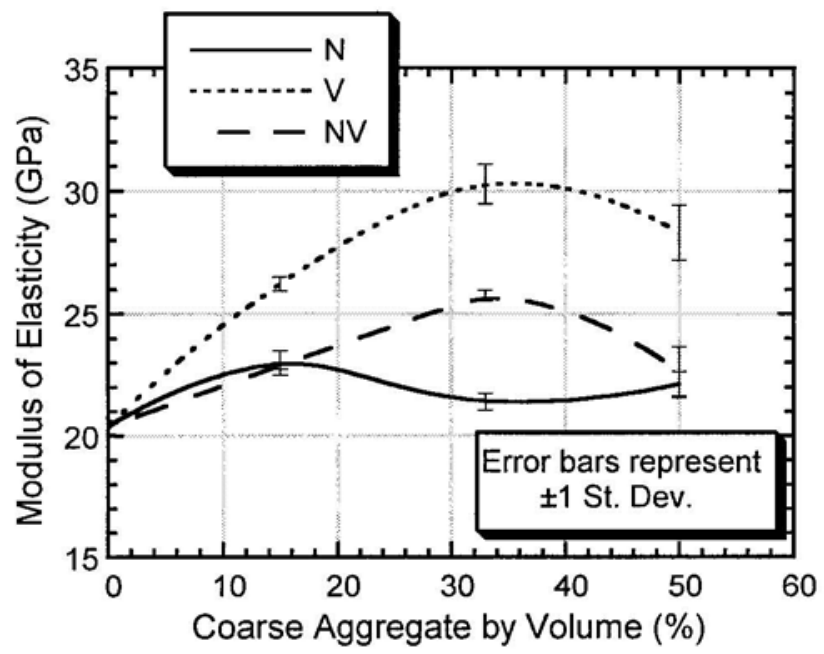

FIG. 6. Modulus of Elasticity versus Coarse Aggregate Content

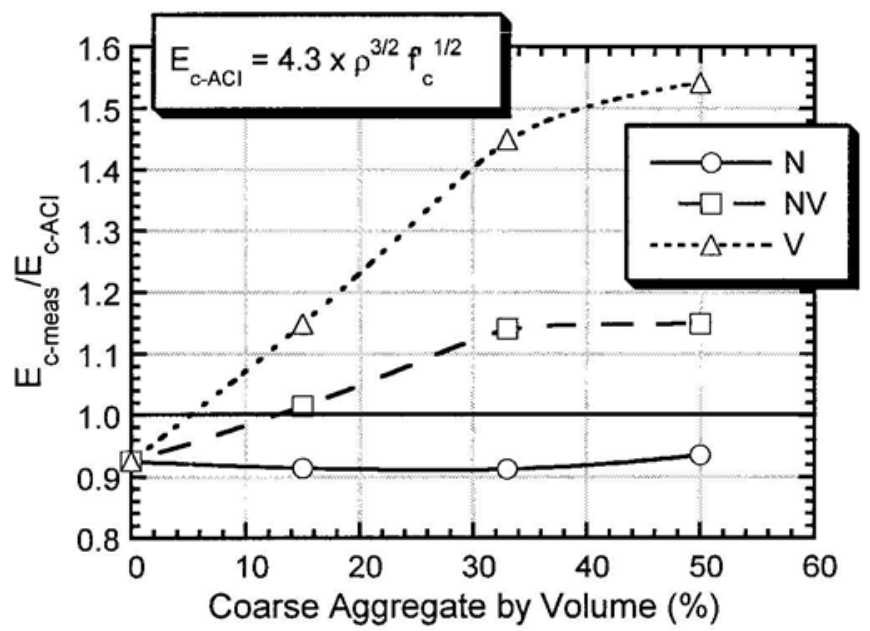

FIG. 7. $E_{c \text {-meas }} / E_{c \text {-ACI }}$ versus Coarse Aggregate Content

decrease. The decrease in the modulus is due to the angularity of the vitrified soil aggregate and the inability of the concrete to compact properly.

For comparison purposes, the modulus of elasticity, $E_{c-\mathrm{ACI}}$, in GPa is calculated using the ACI equation (ACI 1995)

$$
E_{c-\mathrm{ACI}}=4.3 \times 10^{-5} \rho^{3 / 2} \vee f_{c}^{\prime}
$$

where $\rho$ is the density of the concrete in kilograms per cubic meter and $f_{c}^{\prime}$ is the 28 day compressive strength in megapascals. These values are given in Table 3 . The variation in the unit weight of the concrete batches is small. On the other hand, the range of compressive strengths is high, from 16.0 MPa for $50 N V$ to $29.8 \mathrm{MPa}$ for $15 N$. Fig. 7 shows the ratio of the measured modulus of elasticity to the modulus of elasticity 


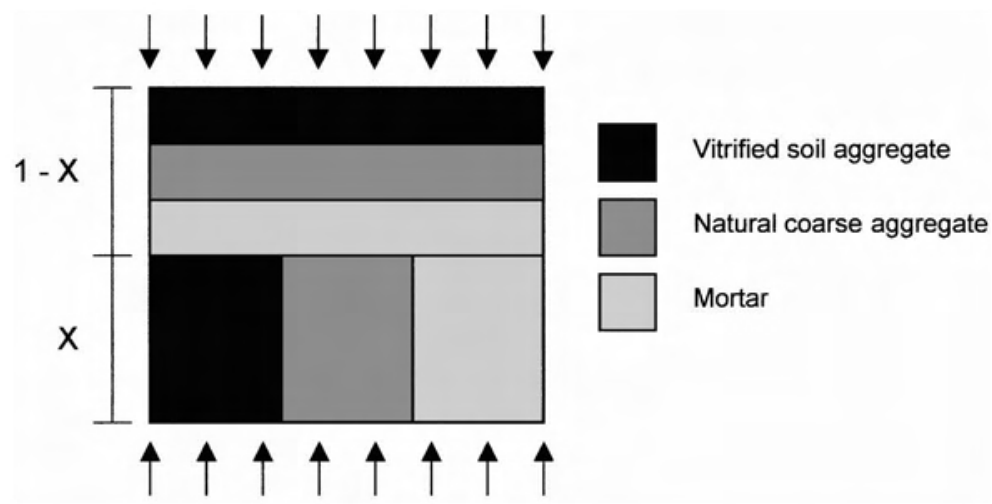

FIG. 8. Modified Hirsch-Dougill Model for Three-Phase Material

found from the ACI equation versus coarse aggregate content. The modulus of elasticity calculated using the ACI equation is relatively close to the measured values for concrete with natural coarse aggregate; however, the ACI equation underestimates the modulus of elasticity for concretes with vitrified soils by as much as $50 \%$. This underestimation is more significant for concretes with higher volume contents of vitrified soil because the ACI equation does not directly account for aggregate stiffness.

A modified Hirsch-Dougill model is used to approximate the modulus of elasticity for a three-phase material consisting of mortar, natural coarse aggregate, and vitrified soil aggregate, as shown in Fig. 8. The original Hirsch-Dougill model is a combined parallel and series spring model for predicting the modulus of elasticity for two-phase materials (Dougill 1962; Hirsch 1962). The two-phase Hirsch-Dougill model has frequently been used to predict the elastic modulus of concrete or aggregates and gives comparable results for other relatively simple models (Baalbaki et al. 1992; Zhou et al. 1995). The modified three-phase Hirsch-Dougill model for predicting the modulus of elasticity, $E_{c \text {-pred }}$, has the following form:

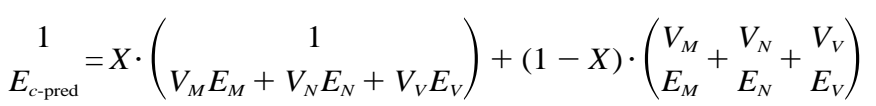

where $E_{M}, E_{N}, E_{V}, V_{M}, V_{N}$, and $V_{V}$ correspond to the moduli of elasticity and the volume fractions of the mortar, natural coarse aggregate, and vitrified soil aggregate, respectively. For isotropic conditions, $X$ has been shown to be equal to 0.5 (Dougill 1962). Using this equation and taking the modulus of elasticity of the mortar to be $20.4 \mathrm{GPa}$ as measured, $E_{N}$ and $E_{V}$ were determined to be 25.5 and $68.3 \mathrm{GPa}$, respectively, from least squares regression. Although the modulus of elasticity for the vitrified soil appears high in comparison to the natural coarse aggregate, it is consistent with values reported by Tuan and Dass (1996). The moduli of elasticity from concrete batches with $50 \%$ aggregate content were omitted when performing the analysis since inadequate compaction occurred as discussed previously. Fig. 9 shows the ratio of the measured modulus of elasticity to the modulus of elasticity from the modified Hirsch-Dougill model versus coarse aggregate content. The modified Hirsch-Dougill model slightly overpredicts the measured modulus of elasticity; however, it is accurate for batches $N V$ and $V$ up to $33 \%$ coarse aggregate content.

\section{Poisson's Ratio}

For the batches with $33 \%$ coarse aggregate content or less, Poisson's ratio remained within the range of 0.19 to 0.22 , as can be seen in Fig. 10. As shown in Figs. 4(b-c), the stress versus lateral strain curves were nearly identical within the elastic range regardless of coarse aggregate type; however, as

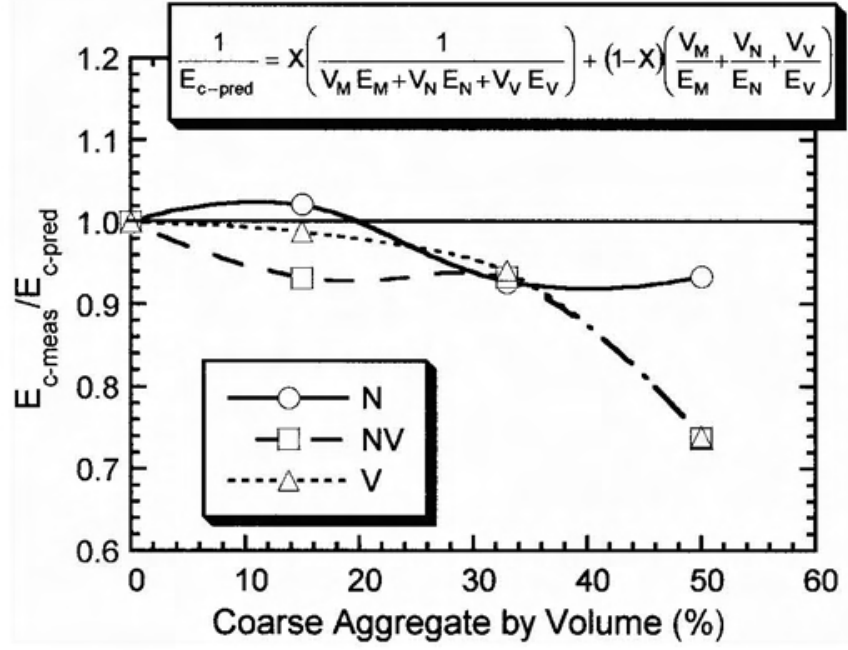

FIG. 9. $E_{c \text {-meas }} / E_{c \text {-pred }}$ versus Coarse Aggregate Content

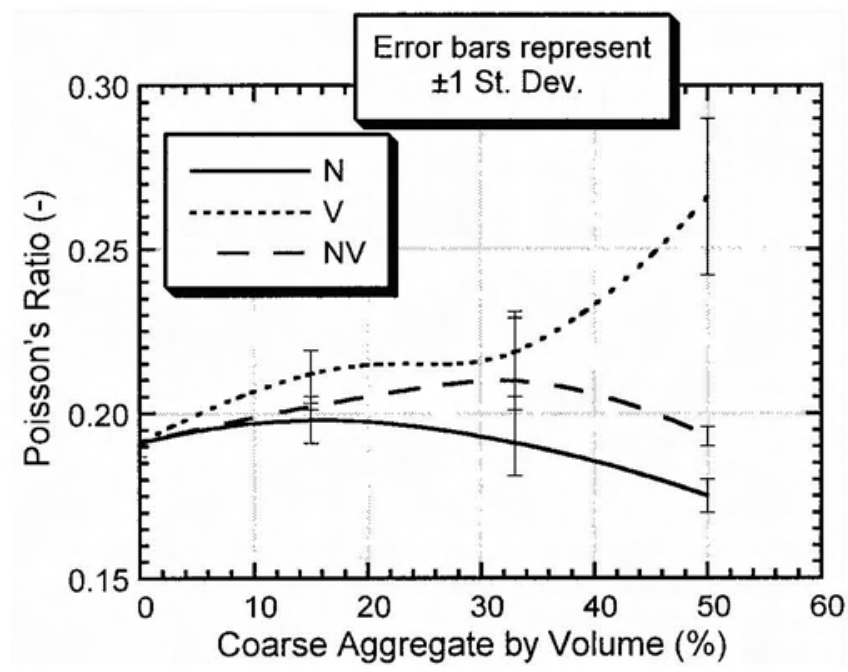

FIG. 10. Poisson's Ratio versus Coarse Aggregate Content

discussed earlier, the higher the vitrified soil content, the higher the modulus of elasticity. This results in consistently higher Poisson's ratios as the natural aggregate is replaced with vitrified soil, as shown in Fig. 10. This trend can be attributed to the lack of bond between the mortar and vitrified soil, allowing increased lateral separation of vertical preexisting bond cracks (Struble et al. 1980).

For batch $50 \mathrm{~V}$, Poisson's ratio increased considerably to 0.27 . As before, the lack of bond is a contributing factor. However, this effect is magnified by the contact between the ag- 
gregates due to the high angularity of the vitrified soils and the large amount of air that was entrapped in this batch.

\section{CONCLUSIONS}

This study examined how different volume fractions of vitrified soil aggregate affect the mechanical performance of concrete in comparison to concrete made with natural coarse aggregate. The following conclusions were found:

1. Vitrified soil aggregates have poor shape; they tend to be elongated in shape with sharp edges. This caused the concrete mixes to become very stiff when large volume fractions of vitrified soils were used.

2. The surface texture of the vitrified soil aggregate is smooth. This texture caused the bond between the mortar and the aggregate to be poor.

3. As the volume fraction of vitrified soil increases, the compressive strength decreases. These findings are similar to those found by other writers examining the use of glass as an aggregate and are attributed to the poor bond between mortar and vitrified soil.

4. Vitrified soil has a high modulus of elasticity, and the modulus of elasticity of concrete can be increased considerably if vitrified soil is used.

5. The ACI equation underestimated the modulus of elasticity for concrete with vitrified soil by more than $30 \%$ in some instances. A modified Hirsch-Dougill model was employed to accurately predict the modulus of elasticity for concrete with up to $33 \%$ mixed coarse aggregate content.

\section{ACKNOWLEDGMENTS}

The writers thank the Tufts Institute for the Environment for financial assistance, and the National Science Foundation for additional funding provided by Grant No. EEC-9633753. The writers also thank Retech Inc. of Ukiah, California, which supplied the vitrified soil, and the geology department at Tufts University for use of equipment to crush the vitrified soil.

\section{REFERENCES}

Al-Manaseer, A. A., and Dalal, T. R. (1997). "Concrete containing plastic aggregates." Concrete Int., 19(5), 47-52.

Ali, M. M., and Greenwell, D. P. (1998). "Concrete change.” Civ. Engrg., ASCE, 68(2), 70-72.

American Concrete Institute (ACI) Committee 318. (1995). "Building code requirements for structural concrete and commentary." Farmington Hills, Mich.

ASTM. (1994). Annual book of standards, concrete and aggregates, Vol. 4.02, Philadelphia, Pa.

Baalbaki, W., Aitcin, P.-C., and Ballivy, G. (1992). "On predicting modulus of elasticity in high-strength concrete." ACI Mat. J., 89(5), 517520.

Brown, B. (1998). “Aggregates for concrete.” Concrete, 32, 12-14.

Delwar, M., Fahmy, M., and Taha, R. (1997). "Use of reclaimed asphalt pavement as aggregate in portland cement concrete." ACI Mat. J., 94(3), 251-256.

Dougill, J. W. (1962). "Discussion of 'Modulus of elasticity of concrete affected by elastic moduli of cement paste matrix and aggregate,' by T. J. Hirsch." ACI J. Proc., 59(9), 1363-1365.

Eldin, N. N., and Senouci, A. B. (1993). "Rubber-tire particles as concrete aggregate." J. Mat. in Civ. Engrg., ASCE, 5(4), 478-496.

Giaccio, G., and Zerbino, R. (1986). "Factors affecting cement pasteaggregate bond." Proc., 8th Int. Congr. on Chem. of Cement, Rio De Janeiro, Brazil, 6, 331-333.

Hansen, J. E., and Fitzpatrick, V. F. (1991). "In situ vitrification applications." 3rd Forum on Innovative Haz. Waste Treatment Technols.: Domestic and Int., Dallas, EPA/540/2-91/015, 325-341.

Hirsch, T. J. (1962). "Modulus of elasticity of concrete affected by elastic moduli of cement paste matrix and aggregate." ACI J. Proc., 59(3), $427-451$.

Meyer, C., Baxter, S., and Jin, W. (1996). "Potential of waste glass for concrete masonry blocks." Proc., 4th Mat. Engrg. Conf.: Mat. for New Millennium, K. P. Chong, ed., ASCE, Reston, Va., 666-673.

"Navistar foundry recycles 350 tons a day of dust and spent sand into usable product." (1998). Nat. Engr., 102, 26-28.

Polley, C., Cramer, S. M., and de la Cruz, R. V. (1998). "Potential for using waste glass in portland cement concrete." J. Mat. in Civ. Engrg., ASCE, 10(4), 210-219.

Raghavan, D., Huynh, H., and Ferraris, C. F. (1998). "Workability, mechanical properties, and chemical stability of recycled tyre rubber-filled cementitious composite." J. Mat. Sci., London, 33(7), 1745-1752.

Ramamurthy, K., and Gumaste, K. S. (1998). "Properties of recycled aggregate concrete." Indian Concrete J., Bombay, 72(1), 49-53.

Shelburne, W. M., and Degroot, D. J. (1998). "Use of waste and recycled materials in highway construction." Civ. Engrg. Pract., 13(1), 5-16.

Shin, C. J., and Sonntag, V. (1994). "Using recovered glass as construction aggregate feedstock." Transp. Res. Rec. 1437, 8-18.

Struble, L., Skalny, J., and Mindess, S. (1980). "Review of cementaggregate bond." Cement and Concrete Res., 10(2), 277-286.

Tavakoli, M., and Soroushian, P. (1996). "Strengths of recycled aggregate concrete made using field-demolished concrete as aggregate." ACI Mat. J., 93(2), 182-190.

Tuan, C. Y., and Dass, W. C. (1996). "Mechanical properties of vitrified soils." Proc., 4th Mat. Engrg. Conf.: Mat. for New Millennium, K. P. Chong, ed., ASCE, Reston, Va., 731-740.

U.S. Department of Defense Environmental Technology Transfer Committee (USDoD). (1994). Remediation technologies screening matrix and reference guide. EPA/542/B-94/013, Nat. Service Ctr. for Envir. Publs., Cincinnati, Ohio.

Yip, W. K., and Tay, J. H. (1990). "Aggregate made from incinerated sludge residue." J. Mat. in Civ. Engrg., ASCE, 2(2), 84-93.

Zhou, F. P., Lydon, F. D., and Barr, B. I. G. (1995). "Effect of coarse aggregate on elastic modulus and compressive strength of high performance concrete." Cement and Concrete Res., 25(1), 177-186.

\section{NOTATION}

The following symbols are used in this paper:

$$
\begin{aligned}
E_{c}, E_{M}, E_{N}, E_{V}= & \text { modulus of elasticity of concrete, mortar, } \\
& \text { natural coarse aggregate, and vitrified soil } \\
& \text { aggregate, respectively; } \\
E_{c \text {-meas }}, E_{c \text {-pred }}, E_{c-\mathrm{ACI}}= & \text { modulus of elasticity from measurements, } \\
& \text { prediction, and ACI equation, respec- } \\
& \text { tively; } \\
f_{c}^{\prime}= & 28 \text {-day compressive strength; } \\
V_{M}, V_{N}, V_{V}= & \text { volume fractions of mortar, natural coarse } \\
& \text { aggregate, and vitrified soil aggregate, } \\
& \text { respectively; } \\
X= & \text { ratio constant modulus of elasticity } \\
& \text { model; } \\
v= & \text { Poisson's ratio; and } \\
\rho= & \text { unit weight of concrete. }
\end{aligned}
$$

